\title{
ASCITE CRÔNICA COMO MANIFESTAÇÃO INICIAL DO LÚPUS ERITEMATOSO SISTÊMICO (LES).
}

\section{CHRONIC ASCITES AS FIRST MANIFESTATION OF SYSTEMIC LUPUS} ERYTHEMATOSUS

Valderílio Feijó Azevedo"; Alais Daiane Fadini Kleinfelder ${ }^{1}$; Natália Bassalobre Galli ${ }^{1}$

\section{RESUMO}

A O caso clínico de uma mulher de 23 anos, com lúpus eritematoso sistêmico, que desenvolveu peritonite crônica e ascite como sua primeira manifestação clínica é descrito. Os principais achados que levaram ao diagnóstico foram plenitude e dor abdominal, hérnia umbilical e ascite. Houve boa resposta ao tratamento com prednisona e hidroxicloroquina.

Palavras-Chave: Lupus, Ascite

\section{ABSTRACT}

A 23 year old woman with systemic lupus erythematosus who developed chronic lupus peritonitis and ascites as her first clinical manifestation is described. The key findings for the diagnosis were abdominal fullness and pain, umbilical hernia, and ascites. The ascites responded well to treatment with prednisone and hydroxychloroquine.

Key-Words: Lupus, Ascites. 


\section{INTRODUÇÃO}

Lúpus Eritematoso Sistêmico (LES) é uma doença autoimune, de caráter inflamatório crônico, caracterizada por acometimento sistêmico e pela presença de fator antinuclear (FAN) em 99\% dos casos $^{1}$. O LES acomete principalmente mulheres com menos de 40 anos $^{2}$. Dentro dos 11 critérios do American College of Rheumatology utilizados para o diagnóstico de LES, encontra-se a manifestação clínica de serosite, inflamação das membranas serosas ${ }^{3}$, que ocorre em aproximadamente $16 \%$ dos pacientes com LES. A serosite acomete principalmente a pleura e 0 pericárdio ${ }^{4}$. Já o envolvimento peritoneal é muito raro, e se apresenta clinicamente por sinais semiológicos de ascite associado à dor, distensão e desconforto abdominal5. Existem casos raros nos quais se relata a ascite como manifestação inicial do LES. Na maioria dos casos outras manifestações clinicas desta enfermidade se apresentam concomitantemente a ascite. Ou ainda, o comprometimento do peritônio ocorre após outras manifestações sistêmicas.

\section{OBJETIVO}

Relatar caso no qual a ascite lúpica se destaca como a primeira manifestação do LES; discutir sua apresentação clínica, diagnótico, fisiopatologia e o tratamento.

\section{RELATO DO CASO}

Paciente feminina de 23 anos, encaminhada ao ambulatório de Reumatologia do Hospital Angelina Caron em julho de 2012 com queixa de dor e aumento progressivo de volume abdominal. A queixa se iniciou há nove meses, associada ao surgimento de hérnia umbilical e poliartrite migratória em joelhos, mãos e punhos. A paciente referiu também perda ponderal de $7 \mathrm{~kg}$ e exacerbação de queda de cabelos nos últimos quatro meses, úlceras orais recorrentes, astenia, presença de erupções eritematosas descamativas em região malar após exposição solar, além de episódios frequentes de cefaléia intensa não responsiva a analgésicos potentes. Durante investigação anterior, foi confirmada presença de ascite por meio de tomografia computadorizada (TC). No entanto nenhum diagnóstico etiológico foi definido. Paciente relatou ainda história de hepatite $A$ na infância. Negava etilismo, drogadição e tabagismo. Ao exame físico, apresentava-se normocorada, acianótica, anictérica, afebril, emagrecida e com presença de úlceras orais em lábio inferior. Foi detectado edema e derrame articular em ambos os punhos e em 2a articulação interfalangeana proximal direita. A força muscular de membros estava preservada. Não foram encontradas alterações no exame cardiovascular e respiratório. 0 abdome mostrou-se distendido, globoso com presença de circulação colateral, sinal de Piparote positivo e macicez móvel de flancos. Fígado e baço não foram palpáveis. Nenhuma alteração de pele foi encontrada.

Em investigação anterior, há cerca de cinco meses, a paciente apresentou FAN de 1/360 com padrão reticular denso; proteína $C$ reativa de 0,01 $\mathrm{mg} / \mathrm{dl}$; fator reumatoide, antimitocôndria, anti-LKM 1, antimúsculo liso não reagentes; sorologia positiva para hepatite $A$; anemia normocitica normocromica; PPD negativo e exames de função hepática e renal inalterados.

A ecografia abdominal sugeriu volumosa ascite confirmada pela TC de abdome superior. Para complementação da investigação, outros exames laboratoriais foram realizados. Notou-se complemento sérico e crioglobulinas normais; ALT, AST, GGT, LDH dentro da faixa de referência. O hemograma não apresentou alterações. Uréia, creatinina, proteína de 24 horas e albumina sérica encontravam-se dentro da normalidade. A punção do líquido ascítico revelou contagem global de leucócitos de $53,33 / \mathrm{mm}^{3}$, LDH de $205 \mathrm{U} / \mathrm{L}$, hemácias de $2.304 / \mathrm{mm}^{3}$, proteínas totais de $4,8 \mathrm{mg} / \mathrm{dl}$, glicose de $92 \mathrm{mg} / \mathrm{dl}$ e gradiente de Albumina Soro-Ascite (GASA) de 0,83. Pesquisa de células LE, bacterioscopia e citologia oncótica no líquido ascitico foram negativas.

A exclusão das causas mais comuns de ascite exsudativa corroborou com a hipótese de ascite decorrente do LES. Dessa forma, foi instituído tratamento com hidroxicloroquina $400 \mathrm{mg} / \mathrm{dia}$ e prednisona $80 \mathrm{mg} /$ dia. Após um mês de tratamento, a paciente apresentou melhora substancial do quadro com o desaparecimento de todos os sintomas acima relatados. Após a retirada escalonada de prednisona de $80 \mathrm{mg} /$ dia para $30 \mathrm{mg} /$ dia e manutenção da dose de hidroxicloroquina, houve recidiva do quadro de ascite em seis meses, sendo necessário tratamento com uso de prednisona $50 \mathrm{mg} /$ dia e punção do líquido ascítico para alívio sintomático. Houve resolução do quadro em três semanas. Atualmente a paciente não apresenta sinais de ascite e mantem uso de $10 \mathrm{mg}$ de prednisona diário associado à hidroxicloroquina.

\section{DISCUSSÃO}

A inflamação das membranas serosas, apesar de inespecífica, é relativamente frequente, acometendo cerca de $16 \%$ dos pacientes com LES. Dentre as serosites, apenas $30 \%$ correspondem à peritonite associada à ascite4. No entanto, em um estudo de necropsias, constatou-se que 60 a $70 \%$ dos pacientes com LES apresentavam peritonite, mas apenas $10 \%$ dos casos foram diagnosticados 
clinicamente6. A serosite pode causar dor, acúmulo de fluidos, criação de aderências e fibrose. A serosite reflete a atividade da doença, mas não foi encontrado nenhum anticorpo relacionado a esta manifestação ${ }^{7}$.

No caso aqui relatado, a paciente apresentou ascite de início insidioso como manifestação precoce do LES. Na prática médica, frente a um quadro de ascite detectado por métodos semiológicos, a primeira conduta é a realização da paracentese diagnóstica com análise do líquido ascítico para definir a etiologia. $O$ GASA auxilia a diferenciação das ascites causadas por transudação ou exsudação de líquidos. Ainda assim, peritonite lúpica como causa de ascite deve ser um diagnóstico de exclusão, sendo necessária diferenciação com as causas mais frequentes de ascite, como: insuficiência cardíaca congestiva (ICC), pericardite constritiva, síndrome nefrótica, Síndrome de Budd-Chiari, enteropatia perdedora de proteínas e neoplasias. peritoneais ${ }^{8,9}$.

Em nossa paciente, foram descartadas infecções, como tuberculose, e neoplasias, devido à cultura negativa de bactérias e ausência de células malignas no líquido ascítico. A paciente não apresentava sinais de ICC ou pericardite constritiva no exame físico. A ausência de alterações nos níveis de albumina sérica e na urinálise descartaram o diagnóstico de síndrome nefrótica. A Síndrome de Budd-Chiari foi excluída pela presença de enzimas hepáticas normais. A TC não apresentava sinais sugestivos de cirrose hepática ou pancreatite. Com a exclusão das causas mais freqüentes de ascite, a hipótese de ascite lúpica foi corroborada devido à presença de líquido ascítico com GASA inferior a 1,1 e demais características típicas de uma causa inflamatória9 ${ }^{9}$ associado à clínica de oligoartrite, alopecia, úlceras orais e rash malar.

A ascite crônica causada por peritonite secundária ao LES tem início insidioso e gradativo, raramente ocorre como manifestação inicial do LES e geralmente apresenta-se acompanhada de manifestações da doença ativa ${ }^{8,10}$. Pode causar dor devido à distensão abdominal e ao efeito compressivo de vísceras. A patogênese da peritonite lúpica inclui deposição de imunocomplexos no peritônio e vasculite dos pequenos vasos do peritônio e da membrana serosa de órgãos abdominais ${ }^{11}$. Na peritonite lúpica crônica, anti-DNA e células LE podem ocasionalmente ser encontrados, mas não é mandatório e não excluem outras causas de ascite ${ }^{12}$.

O prognóstico costuma ser favorável se houver tratamento adequado, baseado na utilização de antiinflamatórios não hormonais e corticosteróides. Em casos refratários, pode ser necessário o uso de imunomoduladores ou imunossupressores ${ }^{11,13}$. A recorrência da ascite é frequente, mas normalmente responde bem ao aumento na dose da corticoterapia. Paracentese de alívio é necessária quando há derrame suficiente para causar efeitos mecânicos de compressão ${ }^{3}$.

\section{CONCLUSÃO}

O diagnostico da ascite secundária à peritonite lúpica é eminentemente clínico, através da exclusão dos diagnósticos diferenciais e da análise do líquido ascítico. Dessa forma, a realização de anamnese e exame físico adequados permitem a identificação etiológica da ascite e o manejo correto do tratamento.

\section{REFERÊNCIAS}

1. Rahman AID. Systemic lupus erythematosus. N Engl J Med. 2008;358(9):929-939.

2. D'cruz DP et al. Sistemic lupus erythematosus. The Lancet. 2007;369:587-596.

3. Hochberg MC. Updating the American College of Rheumatology revised criteria for the classification of systemic lupus erythematosus. Arthritis Rheumatology. 1925;40(9).

4. Man BL. Serositis related to systemic lupus erythematosus: prevalence and outcome. Lupus. 2005;14:822-826.

5. Mok CC. Investigations and management of gastrointestinal and hepatic Manifestationsof systemic lupus erythematosus. Best Practice \& Research Clinical Rheumatology. 2005;19(5):741-766.

6. Takeno MIY. Intestinal manifestations in systemic lupus erythematosus. Intern Med. 2006;45(2):41-42.

7. Prasad S, Abujam B, Lawrence A, Aggarwal A. Massive ascites as a presenting feature of lupus. International journal of rheumatic diseases. 2012;15(1):e15-6. Available at: http://www.ncbi.nlm.nih.gov/pubmed/22324961.

8. Schousboe JT, Koch AE. Chronic lupus peritonitis with ascites: review of the literature with a case report. Semin Arthritis Rheum. 1988;18:121-126.

9. Forouhar-Graff H, Dennis-Yawingu K, Parke A. Insidious onset of massive painless ascites as initial manifestation of systemic lupus erythematosus. Lupus. 2011;20(7):754-7. Available at: http://www.ncbi.nlm.nih.gov/pubmed/21335398. Accessed February 25, 2014. 


\section{RELATO DE CASO}

10. Weinstein PJNC. Rapid onset of massive ascites as the initial presentation of systemic lupus erythematosus. Am J Gastroenterol 2000. 2000;95(1):301-302.

11. Júnior HP et al. Ascite por peritonite lúpica: uma forma rara de início do lúpus eritematoso sistêmico. Rev Bras REumatol. 2012;52(1):116-119.

12. Hou WSA. Ascites: diagnosis and management. Med Clin North Am. 2009;93(4):801-8017.

13. Kaklamanis $P$ et al. Chronic lupus peritonitis with ascites. Annals of the rheumatic diseases. 1991;50(3):176-7. 